\title{
Q\&A: What did Charles Darwin prove?
} Paul Harvey

\section{It is often said that Darwin's theory of natural selection is unproven - True?}

I don't think that is a very useful question because Darwin's strength comes not so much from what he proved, but from the near-inescapable conclusions that he led us to. He used every means of informing himself about questions that interested him. $\mathrm{He}$ is known for his massive and continuous correspondence, always asking pertinent questions of those studying what we should now call model systems or model organisms. Of course, he was also a great natural historian himself, so his own observations pervade his writings. He was then able to integrate observations from one species into a prototype for what we now call the comparative method - he looked across species and showed how similar environments resulted in the development of similar adaptations. When making crossspecies comparisons it is important to distinguish between similarity through inheritance from a common ancestor and similarity through independent evolutionary origins.

\section{But isn't the comparative method that uses inference from independent evolutionary origins a recent development?}

Yes, many of us have made a big deal of developing and applying new

Paul Harvey, Department of Zoology, University of Oxford, The Tinbergen Building, South Parks Road, Oxford OX1 3PS, UK. Email: paul.harvey@zoo.ox.ac.uk statistical methods, but Darwin was on to the problem. He just did not use statistics and probabilities, which is why I call his method a prototype. For example, he noted that a higher proportion of tree species compared with other plants in Great Britain have male and female flower structures on separate plants. But he went further and showed that this pattern of predominance occurs within many families of trees. Since there is variation within the families, he knew he was not dealing with a single evolutionary event, with subsequent inheritance from an ancestral tree species.

\section{So he wasn't an experimental biologist?}

Yes he was that too, and moreover he was a remarkable one. There is no doubt that some people have the knack of designing simple experiments that minimize the number of alternative explanations for the results. Darwin was one of those. For example, it had been claimed that orchids did not secrete nectar but that they fooled insects into believing they did; the conspicuous nectaries (Figure 1) had no function except to deceive insects into visiting the flower, which thereby transferred its pollen. Darwin simply cut off half the length of the nectaries from some flowers on an orchid head and found that they tended not to get their pollen removed. In another case, he was interested in how carnivorous plants differed in trapping their prey. Just touching the surface filaments of a Venus fly trap (Dionaea) with a delicate human hair (perhaps from one of his young children?) caused the trap to rapidly close; no sticky, viscous fluid was involved. In contrast, a thick human hair (perhaps one plucked from his beard?), dragged across a sundew (Drosera; Figure 2) leaf surface excited no movement in the plant, but resistance from the sticky-surface fluid was marked. Clearly, Venus fly traps catch insect prey in the locked trap while sundew glue them down before digestion. Indeed, it is difficult to understand how a person with Darwin's intellect missed observing Mendelian segregation in his plantbreeding experiments, but he did.

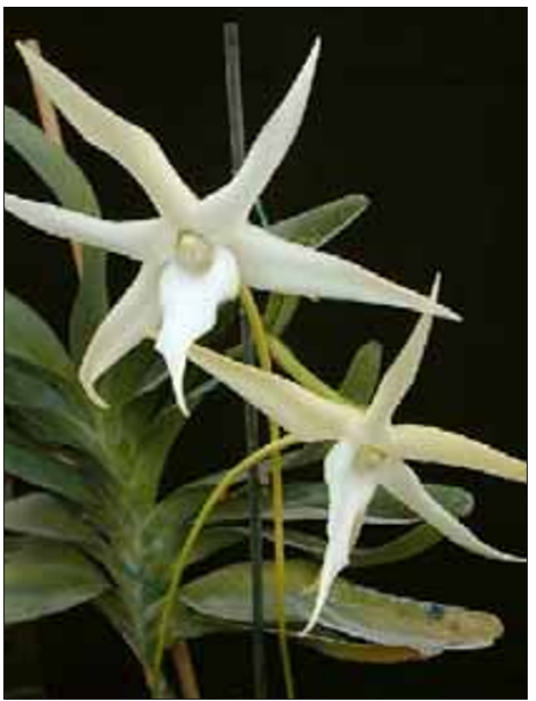

Figure I

The orchid Angraecum sesquipedale (also called Darwin's orchid, Christmas orchid, Star of Bethlehem orchid, King of the Angraecums). The nectary on this species of orchid is 25-30 centimeters ( $10-12$ inches) long. Photograph courtesy Umberto Paris. 


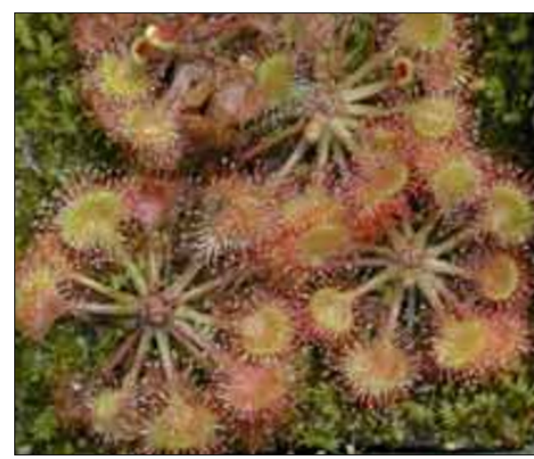

Figure 2

Drosera rotundifolia, the original sundew species studied by Charles Darwin.

Photograph by John Brittnacher, International Carnivorous Plant Society; reproduced with permission.

\section{Are you saying Darwin could be a role model for a 2 Ist-century scientist?}

If you mean by that: Did he pose the same sort of questions in the same way as contemporary biologists? then the answer is yes. Indeed, he set the research agenda that many still follow: as Dobzhansky famously put it "nothing in Biology makes sense except in the light of evolution". That implies that all research biologists are following Darwin's agenda! Of course, he could not have known how to pursue the great unknowns in genetics, or how developmental biology would be incorporated into mainstream evolutionary theory (or what we now call evo-devo). But he did frame many of the unsolved questions for what we would now call organismic biology. He appreciated the importance of sexual selection, that something generally kept sex ratios around 50:50, that altruism must evolve by some interesting process, that distastefulness and warning coloration (see Figure 3 for a classic example) are in some sense adaptations. He didn't exactly know how these things evolved, and even explicitly left some problems to be solved in the future (that is, he admitted that he was stumped). So along came RA Fisher, WD Hamilton and a host of others who were able to use algebra to identify what would evolve as conditions changed. Given that he wasn't particularly numerate, Darwin's logic remains beautiful to read. But, as a 21st-century scientist, his correspondents would have included some theoreticians who could better develop his ideas and force him to state his assumptions with greater clarity.

\section{So he was confused about some things, despite the gargantuan intellect?}

Yes, he was. But it has been pointed out that it is better to get an approximate answer to the right question, however vague, than the right answer to the wrong question, which can always be made more precise! Darwin got the right questions, resulting in the approximate answers. For example, he realized the approximate consequences of accepting blending inheritance or the problems with accepting group selection as a strong evolutionary force. He was not to know that blending inheritance did not occur or that group selection could be redefined as kin selection. If only the advances in genetics had been made in tandem with his work on evolution, then the fog would have lifted.

\section{But Darwin didn't publish papers like a 2 Ist-century scientist, did he?}

I think the answer to that one has to be a resounding no. One thing shines out and that is Darwin's appreciation of the need to reflect at length. Indeed, he went further and argued that his career had taught him that there had not been any instance when he had regretted holding back on publication. The published product, he argued, was all the better for repeated polishing and tinkering. That is virtually unthinkable nowadays, with so many Wallace's in the woodwork. The

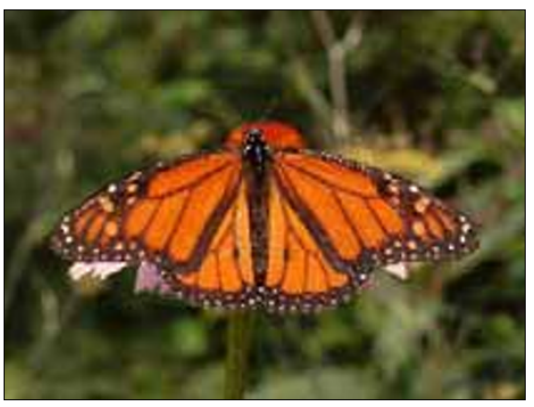

Figure 3

Monarch butterflies (Danaus plexippus) are poisonous and distasteful; this is advertised to potential predators by brightly colored wings. Photograph by Derek Ramsey, reproduced under GFDL I.2 [http://en.wikipedia.org/wiki/ Wikipedia:Text_of_the_GNU_Free_

Documentation_License].

balance has shifted increasingly towards achieving priority. Nevertheless, I still find this a puzzle: how could Darwin have felt so very secure?

\section{What was so special about Darwin?}

Several things. The fact that he kept at his researches at a fairly even rate from the voyage of the Beagle until his death is one of them. There's no doubt in my mind that he could have kept on going for another lifetime - once you have set the conceptual foundation as he did, then the world opens up for you. New questions are around every corner. That is pure joy. But the other side of that is that Darwin didn't seem to age, in the sense that later in life we generally try to fit new facts into a world view that we developed decades before; we build our own phlogiston universes. We have to remind ourselves that, while Darwin was always learning, if he felt that a gradual accumulation of facts questioned a treasured conclusion, then he would revisit that conclusion and all that resulted from it. His increasing acceptance of blending inheritance and its consequences, which I mentioned above, is a case in point. I 
could go on answering this question because Darwin provided me with an agenda at about the age of 15 and I've been with it since. But, I'll make a final point - Darwin could write so well. So well that he expresses himself with enormous clarity across the centuries. Any of us can pick up one of his books and read it with ease and for pleasure. And we'll fairly rapidly find places where Darwin's clarity of style reveals errors of logic, and whether those are because we have learned more in the years since he wrote or because he made some obvious mistakes is for us his readers to decide. If we are up to it.

Published: 23 February 2009

Journal of Biology 2009, 8: I I (doi: I0.I I86/jbioll I8)

The electronic version of this article is the complete one and can be found online at http://jbiol.com/content/8/2/I I

(C) 2009 BioMed Central Ltd 